\title{
New light on visual pigment genes
}

The recent explosion in knowledge about the human genome, resulting from the application of the new methods of molecular genetics, has extended to our understanding of the genes encoding visual pigments. This in turn has given us new insight into the mechanisms of normal and abnormal colour vision as well as basic mechanisms of evolution.

Visual pigments, which reside in the plasma and disc membranes of photoreceptor outer segments, consist of an apoprotein, opsin, covalently linked to 11-cis-retinal, the apoprotein in each visual pigment being encoded by a different gene. The absorption of a photon by a visual pigment results in the isomerisation of retinal from the 11-cis to the all-trans configuration, and this ultimately results in the production of a neural signal.

Recent work by Nathans and his colleagues ${ }^{12}$ started with the assumption that the rod pigment, rhodopsin, and the cone pigments all evolved from a common ancestor and, as a result, would contain similar sequences of nucleotides. Using a bovine rhodopsin gene as a probe, they found that it bound strongly to one segment of human DNA and less strongly to three other DNA segments. The segment to which the bovine rhodopsin gene bound strongly was shown to be the gene encoding human rhodopsin which resides on chromosome $3 .{ }^{34}$ The three segments to which it bound less strongly were shown to be the genes encoding the colour vision pigments, two (the red and the green colour vision genes) being on the $\mathrm{X}$ chromosome and one (the blue colour vision gene) on chromosome $7 .{ }^{2}$ Bovine and human rhodopsin are approximately $90 \%$ identical in DNA sequence, ${ }^{56}$ human rhodopsin and colour pigments are approximately $40 \%$ identical, ${ }^{6}$ while the red and green pigments show only $43 \%$ identity with the blue pigment but $96 \%$ mutual identity. ${ }^{1}$ The fact that the genes encoding the red and green pigments are $96 \%$ identical and are located at the end of the long arm of the $\mathrm{X}$ chromosome suggests that they arose by an evolutionarily recent duplication event.

One unexpected finding was that, while males with normal colour vision have one red pigment gene on each $\mathrm{X}$ chromosome, the number of green pigment genes varied from one to three, ${ }^{1}$ while occasionally there may even be four or more green pigment genes.'

Nathans and his colleagues then studied people with the four classes of red and green colour blindness. People with deuteranopia were found to have a normal red pigment gene but no green pigment gene(s). Those with protanopia lacked a normal red pigment gene, which was replaced by a hybrid red-green pigment gene, and they had no green pigment gene or a variable number of them. Deuteranomalous trichromats had a normal red pigment gene, a hybrid red-green gene, with or without normal gene pigment genes. Protanomalous trichromats had no normal red pigment gene, a hybrid redgreen pigment gene, and a variable number of green pigment genes. These findings were explained by unequal crossovers that resulted in the deletion of a pigment gene or the production of different fusion genes consisting of varying portions of the red and green pigment genes. ${ }^{28}$ People with protanopia and protanomaly appear to have the same genotype (one red-green fusion gene and one intact green gene).
These phenotypic differences could be due to slight differences in the crossover points between the red and green pigment genes, resulting in protein pigments with different in-vivo light sensitivity, causing different colour perception. ${ }^{9}$ Similarly, differences in crossover points could explain the variations that have been described in the degree of impairment in people with anomalous trichromacy (protanomaly and deuteranomaly). The molecular methods used up to the present cannot distinguish between small differences in the position of crossover points.

It is interesting that the gene for $\mathrm{X}$-linked blue cone monochromatism maps to Xq28, the site of the red and green pigment genes. It is possible that this rare disorder, characterised by poor vision, nystagmus, photophobia, and achromatopsia, results from alteration of these two pigment genes so that they do not function, or from their deletion. ${ }^{10}$

The observation that humans and Old World monkeys have red and green pigment genes on their X chromosome while New World monkeys have one long wavelength gene on their X chromosome ${ }^{11}$ has led to the suggestion that short wavelength (blue), long wavelength (red and green), and rod pigments all diverged from a common ancestor more than 500 million years ago, and that the red and green pigment genes were generated, after a duplication event, after the split between New and Old World primates some 30 to 40 million years ago. ${ }^{1}$ An alternative suggestion is that the rhodopsin gene and the common ancestor of the colour pigment genes diverged first, about 800 million years ago, and that the three different colour pigment genes evolved after that. ${ }^{12}$

There is still much to learn about visual pigments, many questions about colour vision that remain unanswered, but already the new genetics has produced exciting avenues for further study.

Moorfields Eye Hospital,

BARRIE JAY

City Road,

London ECIV 2PD

1 Nathans J, Thomas D, Hogness DS. Molecular genetics of human color vision: the genes encoding blue, green, and red pigments. Science 1986; 232: 193 202 .

2 Nathans, J, Piantandida TP, Eddy RL, Shows TB, Hogness DS. Molecular genetics of inherited variation in human color vision. Science 1986; 232: 20310.

3 Sparkes RS, Mohandas T, Newman SL, et al. Assignment of the rhodopsin gene to human chromosome 3. Invest Ophthalmol Vis Sci 1986; 27: 1170-2. Sparkes RS, Klisak I, Kaufman D, Mohandas T, Tobin AJ, McGinnis JF. Assignment of the rhodopsin gene to human chromosome three, region
$3 \mathrm{q} 21-3 \mathrm{q} 24$ by in-situ hybridization studies. Curr Eye Res $1987 ; 5: 797-8$. 3q21-3q24 by in-situ hybridization studies. Curr Eye Res 1987; 5: 797-8.
Nathans J, Hogness DS. Isolation, sequence analysis, and intron-exon

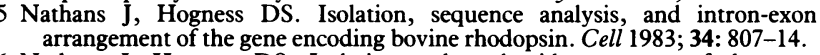
Nathans J, Hogness DS. Isolation and nucleotide sequence of the gene encoding human rhodopsin. Proc Natl Acad Sci USA 1984; 81: 4851-5.

7 Drummond-Borg M, Deeb S, Motulsky AG. Molecular detection of color vision anomalies. Am f Hum Genet 1987; 41 : A96.

8 Vollrath D, Nathans J, Davis RW. Tandem array of human visual pigment genes at Xq28. Science 1988; 240: 1669-72.

9 Drummond-Borg M, Deeb S, Motulsky AG. Molecular basis of abnormal redgreen color vision: a family with three types of color vision defects. Am f H Hm Genet 1988; 43: 675-83.

10 Lewis RA, Holcomb JD, Bromley WC, Wilson MC, Roderick TH, Hejtmancik JF. Mapping X-linked ophthalmic diseases. III. Provisional assignment of the locus for

11 Bowmaker JK, Mollon JD, Jacobs G. Microspectrophotometric results for old and new world primates. In: Mollon JD, Sharpe LT, eds. Colour vision. New York: Academic Press, 1983: 57-68.

12 Yokoyama S, Yokoyama R. Molecular evolution of human visual pigment genes. Mol Biol Evol 1989; 6: 186-97. 